\title{
Basal nitric oxide production is enhanced by hydraulic pressure in cultured human trabecular cells
}

Toshihiko Matsuo

\begin{abstract}
Backgroundlaims-Nitric oxide donors reduce intraocular pressure. Human trabecular cells in culture were examined for their nitric oxide production in response to hydraulic pressure.

Methods-Human trabecular cells were cultured from trabeculum tissue fragments excised during trabeculectomy and exposed to hydraulic pressure change in a culture flask connected to a glass syringe. The pressure was exerted by automatic infusion of the piston of the syringe and monitored by a pressure gauge. The intracellular nitric oxide level was measured in real time with a nitric oxide binding fluorescent dye, diaminofluorescein-2.

Results-Intracellular nitric oxide levels in cultured trabecular cells showed spontaneous fluctuation during 400 seconds of observation. Peak levels of intracellular nitric oxide were significantly higher at hydraulic pressure of 30,40 , and $50 \mathrm{~mm}$ $\mathrm{Hg}$, compared with 0 and $25 \mathrm{~mm} \mathrm{Hg}$ $(p<0.0001$, one way ANOVA, and $p<0.05$, Tukey-Kramer test). The fluctuation was completely abolished by the presence of N-methyl-L-arginine (L-NMMA), a nitric oxide synthase inhibitor. The cultured trabecular cells were shown by immunohistochemistry to express brain nitric oxide synthase (bNOS).

Conclusion-Higher levels of hydraulic pressure enhanced basal production of nitric oxide in human trabecular cells. Nitric oxide would be a physiological mediator in the regulation of intraocular pressure.

(Br F Ophthalmol 2000;84:631-635)
\end{abstract}

Department of Ophthalmology, Okayama University Medical School, 2-5-1 Shikata-cho, Okayama City, 700-8558, Japan T Matsuo

matsuot@cc.okayama-u.ac.jp

Accepted for publication 24 February 2000
Nitric oxide is a short lived free radical, generated from L-arginine by nitric oxide synthases (NOSs) in an enzymatic reaction. It is diffusible across biological membranes and has such diverse roles as an endothelium derived relaxing factor, a neuromodulator, and an immunological mediator in the cardiovascular, nervous, and immune systems, respectively. ${ }^{12}$ In the eye, nitric oxide is a physiological regulator as well as a pathological mediator not only in the vascular system but also in other tissues including the retina and the ocular surface. ${ }^{3}$

Nitric oxide generating substances, called nitric oxide donors, have been shown to reduce the intraocular pressure when applied topically or injected into the anterior chamber or the vitreous. ${ }^{4-10}$ The activity of nitric oxide synthase has been also shown in the trabecular meshwork both immunohistochemically ${ }^{11}$ and enzymatically. ${ }^{12}$

I previously demonstrated that trabecular cells showed a transient rise or oscillation of intracellular calcium when hydraulic pressure reached around $25 \mathrm{~mm} \mathrm{Hg} .{ }^{13}$ Trabecular cells also produced prostaglandin $\mathrm{F}_{2 \alpha}$, tissue inhibitor of metalloproteinase (TIMP)-1, and matrix metalloproteinase (MMP)-2 in response to cyclic mechanical stretching. ${ }^{14}{ }^{15}$ Furthermore, mechanical stretch has been shown to cause transient loss of $\alpha \mathrm{B}$-crystallin, ${ }^{16}$ alter actin cytoskeletal network, ${ }^{17}$ or induce a novel gene ${ }^{18}$ in trabecular cells. In this study, I examined whether trabecular cells would produce nitric oxide in response to hydraulic pressure. Until now, nitric oxide production has been estimated by the measurement of its stable end products such as nitrite and nitrate. ${ }^{19}$ The recent development of a nitric oxide binding fluorescent dye allowed me to monitor intracellular nitric oxide levels in real time..$^{20-23}$

\section{Materials and methods}

CULTURE OF HUMAN TRABECULAR CELLS

Trabeculum tissue fragments excised during trabeculectomy in patients with primary open angle glaucoma (a 60 year old man and a 57 year old woman) were placed in wells of a 24 well multidish (Nunc, Naterville, IL, USA) containing Dulbecco's modified Eagle's medium (DMEM) supplemented with 15\% fetal calf serum, $100 \mathrm{mg} / 1$ streptomycin, and 100 $\mathrm{mg} / \mathrm{l}$ ampicillin, and were incubated under a humidified atmosphere of 5\% carbon dioxide and $95 \%$ air at $37^{\circ} \mathrm{C}$. Cells, grown out of the tissue fragments usually 2-3 weeks after the start of culture, were transferred to a six well multidish and then to $6 \mathrm{~cm}$ petri dishes (Nunc). Morphological features of the cells were the same as those described previously for trabecular cells. ${ }^{24-27}$ 


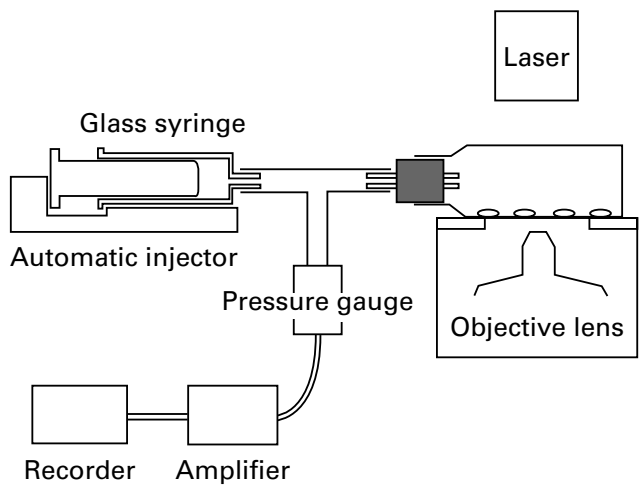

Figure 1 Schematic drawing to show a fluid filled closed system to exert hydraulic pressure on cultured cells. ${ }^{13}$

APPLICATION OF HYDRAULIC PRESSURE AND MEASUREMENT OF INTRACELLULAR NITRIC OXIDE The third to fourth passages of human trabecular cells derived from both patients were used in the following experiment. The cells were transferred to tissue culture polystyrene flasks with an area of $25 \mathrm{~cm}^{2}$ (Iwaki, Funabashi, Japan), and cultured for 3 days. The cells were loaded with $20 \mu M$ of diaminofluorescein-2 diacetate (DAF-2 DA: Daiichi Pure Chemicals, Tokyo, Japan) for 30 minutes at $37^{\circ} \mathrm{C}$ in HEPES buffered saline (10 $\mathrm{mM}$ HEPES, $145 \mathrm{mM} \mathrm{NaCl}, 5 \mathrm{mM} \mathrm{KCl}$, $1 \mathrm{mM} \mathrm{MgCl}_{2}, 1 \mathrm{mM} \mathrm{CaCl}{ }_{2}$, and $10 \mathrm{mM}$ glucose, $\mathrm{pH} 7.4) .^{13}$ For a control experiment, nitric oxide synthase inhibitor, N-methyl-Larginine (L-NMMA: Sigma, St Louis, MO, USA) at a concentration of $0.1,1,10$, or 100 $\mu M$ was administered at the time of dye loading. Cells were washed, and the flask was then filled with HEPES buffered saline.

Hydraulic pressure was exerted on cultured cells in a fluid filled closed system (Fig 1). The flask was placed on the stage of an inverted

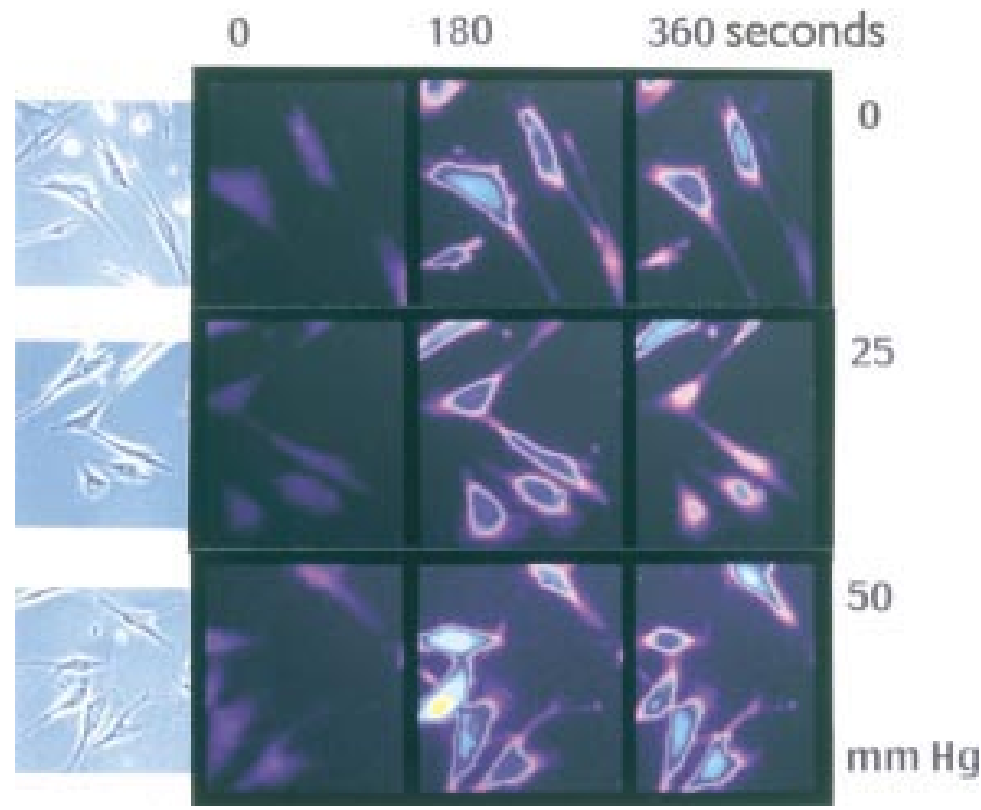

Figure 2 Spontaneous changes in intracellular nitric oxide levels of human trabecular cells at hydraulic pressure of 0,25, and $50 \mathrm{~mm} \mathrm{Hg}$ (top to bottom). Nitric oxide levels are higher at the pressure of $50 \mathrm{~mm} \mathrm{Hg}$, compared with 0 and $25 \mathrm{~mm} \mathrm{Hg}$. Each frame is obtained at 0,180 , and 360 seconds (left to right). Changing intensity of fluorescence, indicative of nitric oxide levels, is shown in pseudocolour. The leftmost column shows phase contrast micrographs of trabecular cells measured for nitric oxide. microscope attached to argon laser (Laser scanning Microspectrofluorometer ACAS570, Meridian Instruments, Okemos, MI, USA), and hydraulic pressure was exerted on the cells. ${ }^{13}$ The pressure inside the flask was elevated by controlled movement of the piston of a $10 \mathrm{ml}$ glass syringe, connected to the flask, by means of an automatic syringe injector (Syringe Infusion Pump, Model 980324, Harvard Apparatus, South Natick, MA, USA), and was monitored continuously by a pressure gauge (LifeKit, Disposable Pressure Monitoring Kit: Nihon Kohden, Tokyo, Japan) which was connected through an amplifier (RMP6004M: Nihon Kohden) to a printer (Mini Recorder SJ-3462: Atto, Tokyo, Japan).

The changes in intracellular nitric oxide of trabecular cells were observed by an excitation wavelength of argon laser at $488 \mathrm{~nm}$ and an emission filter of $530 \mathrm{~nm}$ as the changing intensity of fluorescence every 20 seconds for 400 seconds to obtain 20 images in total. Each culture flask was used only once for the fluorescence measurement at a certain level of hydraulic pressure to avoid the effect of the preceding pressure level. Hydraulic pressure in a flask was zero at the beginning of setup, and then was elevated to either $25,30,40$, or 50
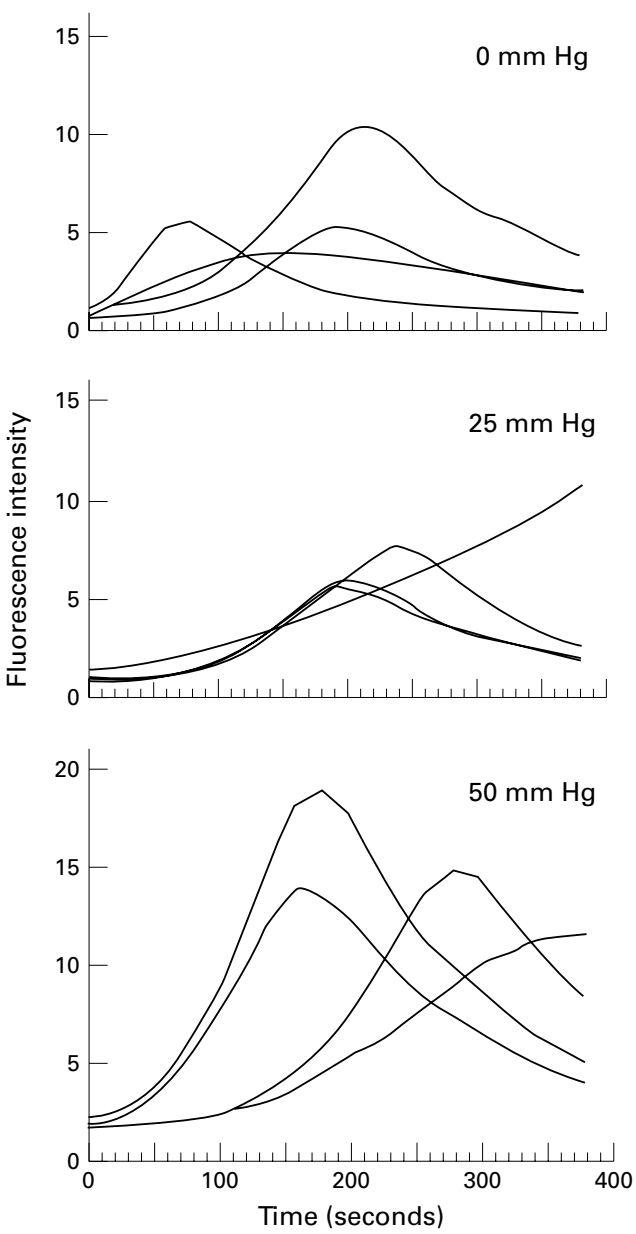

Figure 3 Spontaneous fuctuation of intracellular nitric oxide in each cell at the pressure of 0,25 , and $50 \mathrm{~mm} \mathrm{Hg}$ during 400 seconds of observation. Fluorescence intensity in each cell of the series of 20 images (shown partly in Fig 2) is quantified. Fluorescence intensity is given in arbitrary units. 
$\mathrm{mm} \mathrm{Hg}$. Five flasks were used for each pressure level. Four cells were chosen in a series of images, and the level of fluorescence in each cell at each time point were quantified by integrating fluorescence intensity with the cell area delineated with a polygon (a software attached to ACAS570). A polygon was drawn by tracing the surrounding of a cell with a computer mouse. The highest level of fluorescence in one image out of 20 images was chosen for each cell, and divided by the lowest level of fluorescence at the beginning to obtain a normalised value of fluorescence intensity which was used for statistical analysis $(20$ cells for each pressure level). One way analysis of variance (ANOVA) was to test the null hypothesis that means of fluorescence intensity at five pressure levels were equal. Tukey-Kramer test for multiple comparisons was then used for differences at the alpha level of 0.05 (StatView5.0, SAS Institute Inc, Cary, NC, USA).

\section{IMMUNOHISTOCHEMISTRY}

Cultured cells in $6 \mathrm{~cm}$ petri dishes were fixed for 30 minutes with $4 \%$ paraformaldehyde in phosphate buffered saline (PBS), and were incubated for 30 minutes with $0.3 \%$ hydrogen peroxide in methanol to inactivate endogenous peroxidase. Cells were incubated with normal goat serum for 20 minutes to block nonspecific binding, and then with anti-bNOS or anti-eNOS rabbit antibody (anti-nitric oxide synthase, brain or endothelial, IgG fraction, $\times 500$ dilution, Sigma) for 30 minutes at room temperature. After being washed three times each for 5 minutes with PBS containing $0.05 \%$ Tween-20 (Bio-Rad Laboratories, Hercules, CA, USA), cells were incubated with biotinylated mouse antibody against rabbit IgG for 30 minutes, and washed again. Cells were incubated with avidin and biotinylated horseradish peroxidase macromolecular complex (ABC: Vector Stain Elite ABC Kit, Vector Laboratories, Burlingame, CA, USA) for 30 minutes, and washed. The colour was developed by 3,3'-diaminobenzidine (Sigma Fast DAB Peroxidase Substrate Tablet Set, Sigma) for 30 minutes at room temperature. Normal rabbit serum in place of the primary antibodies served as negative controls. Six dishes were used each for staining of either brain or endothelial nitric oxide synthase, or for control.

\section{Results}

During the observation period of 400 seconds, the basal level of intracellular nitric oxide at hydraulic pressure of $0 \mathrm{~mm} \mathrm{Hg}$ showed a spontaneous increase followed by a decrease with its peak at different time points varying from cell to cell (Figs 2 and 3). This fluctuation of nitric oxide was completely abolished by the addition of L-NMMA, nitric oxide synthase inhibitor, at the concentration of 10 and $100 \mu \mathrm{M}$, while L-NMMA at the concentration of 0.1 and 1 $\mu \mathrm{M}$ did not influence this spontaneous fluctuation. These facts indicated that the increase of nitric oxide was generated by the enzymatic reaction.

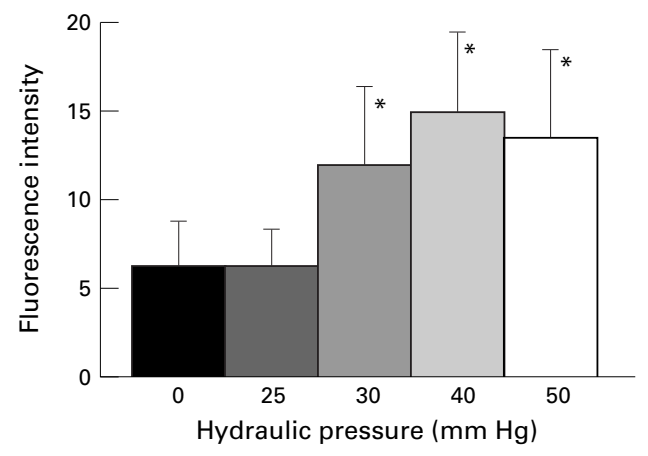

Figure 4 Peak levels of intracellular nitric oxide in human trabecular cells at different levels of hydraulic pressure. Nitric oxide levels are significantly higher at the pressure of 30, 40, and $50 \mathrm{~mm} \mathrm{Hg}$, compared with those at the pressure of 0 and $25 \mathrm{~mm} \mathrm{Hg}(p<0.0001$, one way ANOVA, asterisks: $p<0.05$, Tukey-Kramer test, $n=20$ cells for each pressure level). Fluorescence intensity is normalised by dividing a peak level by a lowest level at the beginning of observation.
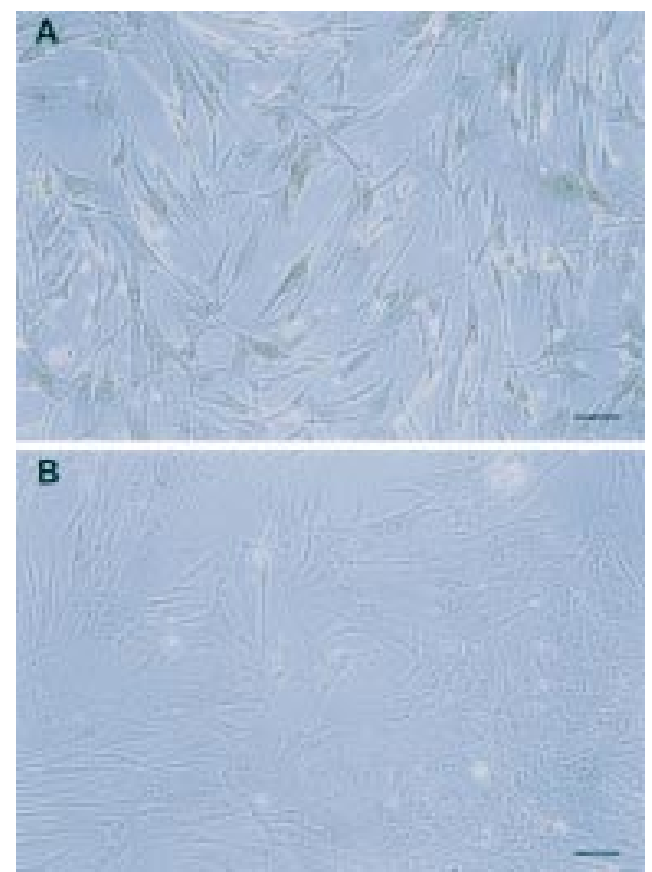

Figure 5 Immunohistochemistry of nitric oxide synthases on human trabecular cells in culture. Trabecular cells are positive for brain nitric oxide synthase $(A)$, while negative for endothelial nitric oxide synthase (B). Bar $=100 \mu \mathrm{m}$.

The level of hydraulic pressure was then elevated to $25,30,40$, or $50 \mathrm{~mm} \mathrm{Hg}$. At the pressure of $25 \mathrm{~mm} \mathrm{Hg}$, neither the latency to a peak nor peak levels of the spontaneous increase of nitric oxide showed any difference from those at the pressure of $0 \mathrm{~mm} \mathrm{Hg}$. When hydraulic pressure was maintained at 30,40 , or $50 \mathrm{~mm} \mathrm{Hg}$, peak levels of the spontaneous increase of intracellular nitric oxide were significantly higher that those at 0 or $25 \mathrm{~mm}$ $\mathrm{Hg}(\mathrm{p}<0.0001$, one way ANOVA, and $\mathrm{p}<0.05$, Tukey-Kramer test, Figs 2, 3, and 4). The preceding incubation with L-NMMA at the concentration of $100 \mu \mathrm{M}$ resulted in no increase of nitric oxide at any pressure level.

Immunohistochemically, human trabecular cells in culture were positive for brain nitric oxide synthase, but negative for endothelial nitric oxide synthase (Fig 5). 


\section{Discussion}

In this study, hydraulic pressure was demonstrated to be one kind of stimulus to enhance basal production of nitric oxide in cultured human trabecular cells. In addition, the threshold of hydraulic pressure for this response lies between 25 and $30 \mathrm{~mm} \mathrm{Hg}$. Human trabecular cells were previously shown to show a transient rise or oscillations of intracellular calcium when hydraulic pressure reached $20-30 \mathrm{~mm}$ $\mathrm{Hg}$ in the same experimental system. ${ }^{13}$ Nitric oxide synthases (bNOS and eNOS) are known to be activated by calcium/calmodulin. ${ }^{12}$ These facts suggest that the enhanced production of nitric oxide is attributable in part to a rise in intracellular calcium.

Spontaneous fluctuation of intracellular nitric oxide levels in each cell was observed even at the pressure of $0 \mathrm{~mm} \mathrm{Hg}$ in the present experiments. This might be attributable to fluid shear force in a culture flask generated by continuous vibration of the stage of the microscope to scan images during the observation period. ${ }^{28-30}$ Laser damage to cells as a possible cause for the nitric oxide increase could be denied by the fact that a spontaneous increase of intracellular calcium was not observed at the pressure of $0 \mathrm{~mm} \mathrm{Hg}$ in this experimental system. ${ }^{13}$ The absence of spontaneous fluctuation of intracellular calcium also indicates that calcium/calmodulin activation of NOS is not the sole mechanism for the increase of intracellular nitric oxide.

The method used in this study to measure intracellular nitric oxide only gives relative values, and its actual concentration cannot be obtained. The degree of a spontaneous increase of intracellular nitric oxide at the pressure of $0 \mathrm{~mm} \mathrm{Hg}$ was about fivefold as much as the baseline level. No assessment can be made whether this increase in intracellular nitric oxide levels of each cell is large or small.

Nitric oxide production has been shown to increase by flow induced shear force, or mechanical strain, stretching, or compression in other types of cells such as vascular endothelial cells, ${ }^{28-37}$ bone cells (osteoblasts), ${ }^{38-40}$ and chondrocytes. ${ }^{4142}$ Human trabecular cells can be added to the list of cells which show nitric oxide production in response to mechanical stimuli. It should be noted that the threshold for nitric oxide production was also determined in this experimental system in which a controlled level of hydraulic pressure could be exerted on cultured cells. Oxygen changes in this fluid filled closed system could be negligible because each measurement was finished within 30 minutes.

Nitric oxide in cultured human trabecular cells was produced by nitric oxide synthase because its production was inhibited by L-NMMA, nitric oxide synthase inhibitor in a dose dependent manner, comparable to a previous study. ${ }^{12}$ Immunohistochemically, the subtype of NOS expressed in cultured human trabecular cells used in this study were demonstrated as bNOS, but not eNOS. In a previous report, trabecular meshwork cells and Schlemm's canal lining cells in histological sections of the human eye showed positive immunoreactivity for eNOS, but not for bNOS, ${ }^{11}$ in contrast with the present result. These contradictory results may be attributed to different specimens of either cultured cells or histological sections used for immunohistochemistry. Based on the embryological evidence that trabecular cells are originated from the neural crest, ${ }^{43}$ it is more consistent that trabecular cells have bNOS which is mainly expressed in the central and peripheral nervous system. On the other hand, cells lining the Schlemm's canal have the same origin as vascular endothelial cells, and naturally share the expression of eNOS with vascular endothelial cells.

Nitric oxide has been shown to induce relaxation of the trabecular meshwork and the ciliary muscle. ${ }^{44}$ Nitric oxide produced by trabecular cells may activate guanylyl cyclase by both an autocrine and paracrine mechanism, leading to an increase of cyclic GMP in trabecular cells. ${ }^{12}$ On the other hand, prostaglandins, for example, are synthesised through direct activation of cyclo-oxygenase by nitric oxide. ${ }^{45}$ Prostaglandins would then diffuse to the ciliary muscle and change the uveoscleral outflow. Nitric oxide may also diffuse to the ciliary muscle and induce its relaxation, ${ }^{44}$ resulting in direct enhancement of the uveoscleral outflow.

A previous study showed a decreased activity of nitric oxide synthase in the trabecular meshwork of glaucomatous eyes. ${ }^{46}$ The decrease in nitric oxide production in the trabecular meshwork may be involved in the development of glaucoma. The production of nitric oxide by trabecular cells in response to hydraulic pressure, as observed in this study, might be absent in these glaucomatous eyes.

In conclusion, trabecular cells produced nitric oxide in response to hydraulic pressure. The threshold for this response lay between 25 and $30 \mathrm{~mm} \mathrm{Hg}$. Trabecular cells would sense the change of intraocular pressure, and nitric oxide could be one of physiological mediators to regulate the intraocular pressure.

The authors are grateful to $\mathrm{Mr}$ Tetsushi Iwasa in the Central Research Laboratories of Okayama University Medical School, and $\mathrm{Mr}$ Katsuyoshi Eguchi at the Okayama Branch of Nihon Kohden for their technical assistance. The study was supported in part by grants in aids for scientific research from the Ministry of Education, Science, Sports, and Culture of Japan.

1 Moncada S, Palmer RMJ, Higgs EA. Nitric oxide: physiology, pathophysiology, and pharmacology. Pharmacol Rev 1991;43:109-42.

2 Bredt DS, Snyder SH. Nitric oxide: a physiologic messenger molecule. Annu Rev Biochem 1994;63:175-95.

3 Becquet F, Courtois Y, Goureau O. Nitric oxide in the eye: multifaceted roles and diverse outcomes. Surv Ophthalmol 1997;42:71-82.

4 Nathanson JA. Direct application of a guanylate cyclase activator lowers intraocular pressure. Eur 7 Pharmacol 1988;147:155-6.

5 Nathanson JA. Nitrovasodilators as a new class of ocular hypotensive agents. F Pharmacol Exp Ther 1992;260:95665.

6 Nathanson JA. Nitric oxide and nitrovasodilators in the eye: mplications for ocular physiology and glaucoma. $f$ Glaucoma 1993;2:206-10.

7 Schuman JS, Erickson K, Nathanson JA. Nitrovasodilator effects on intraocular pressure and outflow facility in monkeys. Exp Eye Res 1994;58:99-105.

8 Wang RF, Podos SM. Effect of the topical application of nitroglycerin on intraocular pressure in normal and glaucomatous monkeys. Exp Eye Res 1995;60:337-9.

9 Behar-Cohen FF, Goureau O, D'Hermies F, et al. Decreased intraocular pressure induced by nitric oxide donors is correlated to nitrite production in the rabbit eye. Invest Ophthalmol Vis Sci 1996;37:1711-15. 
10 Kojima S, Sugiyama T, Shimizu K, et al. Effect of a nitric oxide donor on intraocular pressure. Nippon Ganka Gakkai oxide donor on intraocular pressure. Nippon Gankd

11 Nathanson JA, McKee M. Identification of an extensive system of nitric oxide-producing cells in the ciliary muscle and outflow pathway. Invest Ophthalmol Vis Sci 1995;36:176573.

12 Geyer O, Podos SM, Mittag T. Nitric oxide synthase activity in tissues of the bovine eye. Graefes Arch Clin Exp Ophthal mol 1997;235:786-93.

13 Matsuo T, Matsuo N. Intracellular calcium response to hydraulic pressure in human trabecular cells. Brf Ophthalmol 1996;80:561-6.

14 Matsuo T, Uchida H, Matsuo N. Bovine and porcine trabecular cells produce prostaglandin F2alpha in response to cyclic mechanical stretching. Fpn f Ophthalmol 1996;40: 289-96.

15 Okada Y, Matsuo T, Ohtsuki H. Bovine trabecular cells produce TIMP-1 and MMP-2 in response to mechanical stretching. Fpn f Ophthalmol 1998;42:90-4.

16 Mitton KP, Tumminia SJ, Arora J, et al. Transient loss of alphaB-crystallin: an early cellular response to mechanical alphaB-crystallin: an early cellular response to mechanical

17 Tumminia SJ, Mitton KP, Arora J, et al. Mechanical stretch alters the actin cytoskeletal network and signal transduction in human trabecular meshwork cells. Invest Ophthalmol Vis Sci 1998;39:1361-71.

18 Sato Y, Matsuo T, Ohtsuki H. A novel gene (oculomedin) induced by mechanical stretching in human trabecular cells of the eye. Biochem Biophys Res Commun 1999;259:349-51.

19 Green LC, Wagner DA, Glogowski J, et al. Analysis of nitrate, nitrite, and $\left[{ }^{15} \mathrm{~N}\right]$ nitrate in biological fluids. Anal Biochem 1982;126:131-8.

20 Kojima H, Sakurai K, Kikuchi K, et al. Development of a fluorescent indicator for nitric oxide based on the fluorescein chromophore. Chem Pharm Bull 1998;46:3735 .

21 Nakatsubo N, Kojima H, Kikuchi K, et al. Direct evidence of nitric oxide production from bovine aortic endothelial of nitric oxide production from bovine aortic endothelial cells using new fluorescence indicat

22 Kojima H, Nakatsubo N, Kikuchi K, et al. Detection and imaging of nitric oxide with novel fluorescent indicators: diaminofluoresceins. Anal Chem 1998;70:2446-53.

23 Kojima H, Nakatsubo N, Kikuchi K, et al. Direct evidence of NO production in rat hippocampus and cortex using a new fluorescent indicator: DAF-2 DA. NeuroReport 1998;9: 3345-8.

24 Polansky JR, Weinreb RN, Baxter JD, et al. Human trabecular cells. I. Establishment in tissue culture and growth characteristics. Invest Ophthalmol Vis Sci 1979;18:1043-9.

25 Alvarado JA, Wood I, Polansky JR. Human trabecular cells. II. Growth pattern and ultrastructural characteristics. Invest Ophthalmol Vis Sci 1982;23:464-78.

26 Tripathi RC, Tripathi BJ. Human trabecular endothelium, corneal endothelium, keratocytes, and scleral fibroblasts in primary cell culture. A comparative study of growth primary cell culture. A comparative study of growth characteristics, morphology, and phagocytic activity by light and scan $611-24$.

27 Grierson I, Robins E, Unger W, et al. The cells of the bovine outflow system in tissue culture. Exp Eye Res 1985;40:3546.
28 Davies PF. Flow-mediated endothelial mechanotransduction. Physiol Rev 1995;75:519-60.

29 Ayajiki K, Kindermann M, Hecker M, et al. Intracellular pH and tyrosine phosphorylation but not calcium determine shear stress-induced nitric oxide production in native endothelial cells. Circ Res 1996;78:750-8.

30 Corson MA, James NL, Latta SE, et al. Phosphorylation of endothelial nitric oxide synthase in response to fluid shear stress. Circ Res 1996;79:984-91.

31 Rubanyi GM, Romero JC, Vanhoutte PM. Flow-induced release of endothelium-derived relaxing factor. $\mathrm{Am} \mathcal{F}$ Physiol 1986;250:H1145-9.

32 Hutcheson IR, Griffith TM. Release of endotheliumderived relaxing factor is modulated both by frequency and amplitude of pulsatile flow. Am f Physiol 1991;261:H25762 .

33 Kuchan MJ, Frangos JA. Role of calcium and calmodulin in flow-induced nitric oxide production in endothelial cells. Am f Physiol 1994;266:C628-36.

34 Noris M, Morigi M, Donadelli R, et al. Nitric oxide synthesis by cultured endothelial cells is modulated by flow conditions. Circ Res 1995;76:536-43.

35 Awolesi MA, Sessa WC, Sumpio BE. Cyclic strain upregulates nitric oxide synthase in cultured bovine aortic endothelial cells. f Clin Invest 1995;96:1449-54.

36 Hishikawa K, Luscher TF. Pulsatile stretch stimulates superoxide production in human aortic endothelial cells. Circulation 1997;96:3610-16.

37 Hishikawa K, Nakaki $T$, Suzuki $H$, et al. Transmural pressure inhibits nitric oxide release from human endothelial cells. Eur f Pharmacol 1992;215:329-31.

38 Johnson DL, McAllister TN, Frangos JA. Fluid flow stimulates rapid and continuous release of nitric oxide in osteoblasts. Am $\mathcal{F}$ Physiol 1996;271:E205-8.

39 Smalt R, Mitchell FT, Howard RL, et al. Induction of NO and prostaglandin $\mathrm{E} 2$ in osteoblasts by wall-shear stress but not mechanical strain. Am f Physiol 1997;273:E751-8.

40 Pitsillides AA, Rawlinson SCF, Suswillo RFL, et al. Mechanical strain-induced NO production by bone cells: a possible role in adaptive bone (re)modeling? FASEB $\mathfrak{f}$ possible role in
$1995 ; 9: 1614-22$.

41 Das P, Schurman DJ, Smith RL. Nitric oxide and G proteins mediate the response of bovine articular chondrocytes to fluid-induced shear. F Orthop Res 1997;15:87-93.

42 Lee DA, Frean SP, Lees P, et al. Dynamic mechanical compression influences nitric oxide production by articular chondrocytes seeded in agarose. Biochem Biophys Res Commun 1998;251:580-5.

43 Tripathi BJ, Tripathi RC. Neural crest origin of human trabecular meshwork and its implications for the pathogenesis of glaucoma. Am f Ophthalmol 1989;107:583-90

44 Wiederholt M, Sturm A, Lepple-Wienhues A. Relaxation of trabecular meshwork and ciliary muscle by release of nitric oxide. Invest Ophthalmol Vis Sci 1994;35:2515-20.

45 Salvemini D, Misko TP, Masferrer JL, et al. Nitric oxide activates cyclooxygenase enzymes. Proc Natl Acad Sci USA 1993;90:7240-4.

46 Nathanson JA, McKee M. Alterations of ocular nitric oxide synthase in human glaucoma. Invest Ophthalmol Vis Sci 1995;36:1774-84 